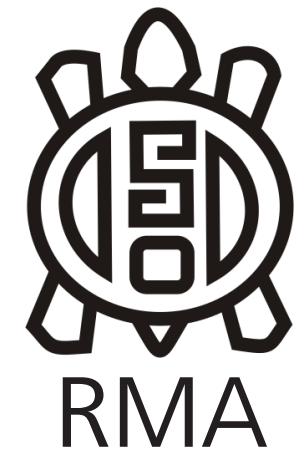

Museología

\section{Cuarenta años de cultura: historiografía de las políticas patrimoniales en el partido de Olavarría (1983-2020)}

Forty years of culture: historiography of patrimonial policies in the Olavarria County (1983-2020)

Nahir Meline Cantar*

\begin{abstract}
*IHAM-FAUD-UNMdP (Instituto del Hábitat y del Ambiente, Facultad de Arquitectura, Urbanismo y Diseño, Universidad Nacional de Mar del Plata). E-mail: nahir.cantar@gmail.com
\end{abstract}

\begin{abstract}
Resumen
La salvaguardia del patrimonio cultural esta fuertemente condicionada por la implementación y continuidad, o discontinuidad, de las políticas culturales que los gobiernos aplican sobre los bienes. Si bien en Argentina existen instituciones y un marco normativo nacional para la protección del patrimonio cultural, así como organismos y regulaciones provinciales específicas para cada jurisdicción, en la provincia de Buenos Aires el destino de gran parte de los bienes del patrimonio está fuertemente condicionado por las políticas aplicadas a nivel local. Bajo esta premisa en el presente trabajo se busca reconstruir las políticas culturales, en general, y patrimoniales, en particular, aplicadas en el Partido de Olavarría desde el retorno de la democracia hasta el año 2020. A partir de este ejercicio, se analiza el impacto que las mismas han tenido sobre los diferentes bienes culturales del partido a lo largo del tiempo. Para ello, se recurre a los métodos de análisis documental y entrevistas en profundidad a informantes clave. El análisis desarrollado demuestra el impacto del compromiso de los dirigentes políticos y de la continuidad en la implementación de políticas culturales en la salvaguardia del patrimonio cultural.
\end{abstract}

Palabras claves: Políticas culturales; Patrimonio cultural; Normativa patrimonial; Gestión local del patrimonio; Olavarría.

\begin{abstract}
The safeguarding of cultural heritage is strongly conditioned by the implementation and continuity, or discontinuity, of the cultural policies that governments apply to the cultural assets. Although in Argentina there are institutions and a national regulatory framework for the protection of cultural heritage, as well as specific provincial organisms and regulations for each jurisdiction, in the province of Buenos Aires the destination of a large part of the heritage assets is strongly conditioned by the policies applied at a local scale.Under this premise, the present work seeks to reconstruct the cultural policies, in general, and patrimonial policies, in particular, applied in the Olavarria County since the return of democracy until 2020. From this exercise, the impact they have had on the different cultural assets of the party over time is analyzed. For this, the methods of documentary analysis and in-depth interviews with key informants are used. The analysis developed shows the impact of the commitment of political leaders and the continuity in the implementation of cultural policies in the safeguarding of cultural heritage.
\end{abstract}

Keywords: Cultural policies; Cultural heritage; Heritage regulations; Local heritage management; Olavarria.

\section{Introducción}

La salvaguardia del patrimonio cultural, y su sustentabilidad sociocultural, está estrechamente vinculada con el impacto y la continuidad de las políticas públicas aplicadas sobre el mismo (Cantar et al. 2021). No obstante, las normativas nacionales y provinciales y los planes y programas destinados a la protección y conservación del patrimonio cultural suelen estar orientados principalmente al patrimonio histórico o monumental de la nación o las provincias, dejando de lado gran parte de los bienes culturales presentes en el territorio. En este contexto, el destino de los bienes que componen gran parte del acervo cultural de las comunidades está condicionado por el impacto de las políticas culturales aplicadas a nivel local.

Las políticas públicas refieren al diseño de acciones colectivas e intencionadas que un gobierno define para alcanzar determinados objetivos. En ese marco, las políticas culturales han sido definidas como: 
"el conjunto de intervenciones llevadas a cabo por el Estado, las instituciones civiles y los grupos comunitarios organizados a fin de orientar el desarrollo simbólico, satisfacer las necesidades culturales de la población y obtener consenso para un tipo de orden o transformación social" (García Canclini 1987:26).

En el desarrollo de las políticas públicas operan "no sólo agentes públicos, sino también privados y comunitarios, construyendo un espacio institucionalizado por organismos estatales, fundaciones, ONGs, tanto municipales, provinciales como nacionales" (Cardini 2013:125). Estas se expresan mediante las leyes y decretos de los poderes legislativos nacional y provinciales, y las ordenanzas y decretos municipales, así como se tornan operativas a través de planes, programas y proyectos ${ }^{1}$.

Cabe destacar, que el accionar y las herramientas de las políticas culturales fue cambiando a lo largo de la historia acorde mutaban los paradigmas de modelo de Estado en los cuales se insertaban, así como la concepción de la cultura que ellos sostenían (García Canclini 1987).

Al igual que en otros países de Latinoamérica, en Argentina, la agenda de las elites gobernantes marcó el inicio de las primeras leyes protectoras del patrimonio que fueron promulgadas en las décadas iniciales del siglo XX: la Ley $N^{\circ} 9.080$ de Ruinas y Yacimientos Arqueológicos y Paleontológicos (1913) y la Ley de Patrimonio Histórico y Artístico $N^{\circ} 12.665$ (1940). Esto coincidió con la creación de organismos dedicados a la gestión del patrimonio, como por ejemplo la Dirección de Parques Nacionales (1934) y la Comisión Nacional de Museos, de Monumentos y de Lugares Históricos (1940).

A partir de las décadas de 1960 y 1970 se produjo en la región un cambio en las políticas culturales. Esas se dieron en un contexto en el cual la UNESCO organizaba conferencias intergubernamentales sobre políticas culturales que, si bien solían estar orientadas a la descripción administrativa y burocrática de dichas políticas, permitieron que se formara:

"cierto sentido común internacional acerca de que el crecimiento de los países no puede evaluarse sólo por índices económicos, y que el desarrollo cultural, concebido como un avance conjunto de toda la sociedad necesita una política pública y no puede ser dejado como tarea marginal a las élites refinadas o librado a la iniciativa empresarial" (García Canclini 1987:17).

\footnotetext{
1 Los planes comprenden el conjunto de objetivos y las reglas dentro de los cuales se enmarcan los programas y los proyectos. Los programas operacionalizan un plan mediante la definición de acciones orientadas a alcanzar las metas y objetivos propuestos dentro de un período determinado. Pueden incluir dentro de su repertorio uno o varios proyectos, los cuales se traducen en acciones concretas, focalizadas, interrelacionadas y coordinadas entre sí (Martínez Nogueira 2010).
}

No obstante, el surgimiento de los gobiernos dictatoriales significó un franco retroceso en materia cultural (Rodríguez 2015).

La recuperación de la democracia y las reformas constitucionales de la década de 1990, de la mano de una importante ampliación de los derechos vinculados con el reconocimiento de la diversidad cultural y de las minorías étnicas, iniciaron en el ámbito nacional procesos que derivaron en importantes cambios normativos y de gestión (Bolán 2013, Colombato 2016, Levrand y Endere 2020).

Acorde a esta coyuntura, en el presente trabajo se analizan las políticas públicas aplicadas al patrimonio del Partido de Olavarría, provincia de Buenos Aires, Argentina, desde 1983 hasta 2020. Para ello resulta necesario abordar, en una primera instancia, la legislación marco de orden nacional y provincial, así como las normas que delimitan la capacidad de acción de los municipios sobre los bienes culturales, es decir aquellas que definen las competencias municipales en la materia. Posteriormente, se reconstruyen las políticas culturales desde 1983 hasta 2020, analizando el contexto político de su gestación, la manera en que fueron aplicadas, su continuidad, y su incidencia en la salvaguarda del patrimonio².

La metodología adoptada para la reconstrucción de las políticas públicas resulta de la convergencia de métodos cualitativos. Por un lado, se utilizó la técnica de análisis documental, la cual implica la realización de un conjunto de operaciones con el fin de describir y representar el contenido de determinados documentos de una manera distinta a su forma original para así facilitar su análisis (Duverger 1981). A partir del empleo de esta técnica se analizó el contenido de la normativa nacional, provincial y municipal aplicable al patrimonio de Olavarría, mediante la recopilación de fuentes legales disponibles en repositorios digitales de carácter oficial. Asimismo, utilizando la misma técnica se reconstruyeron diferentes políticas mediante la consulta de publicaciones científicas y académicas en las que se ha desarrollado la temática para el mismo arco temporal. Como complemento a las fuentes documentales, se realizaron entrevistas semiestructuradas o en profundidad (Scribano 2008, Guber 2011) a nueve observadores privilegiados (Corbetta 2007). La selección de los entrevistados se realizó por un muestreo intencional (Marradi et al. 2010), a partir de los registros de los cargos públicos que ocuparon u ocupan durante el período de estudio o por haber enfocado sus investigaciones en algunas de las problemáticas

\footnotetext{
2 Debido a la extensión del presente artículo, las políticas públicas reconstruidas para el lugar y el arco tiempo seleccionados no se analizarán a la luz de la coyuntura en las que fueron emanadas, es decir, las disputas en torno a su promulgación, las creencias que residen detrás de su formulación, los contextos institucionales y socioculturales, las narrativas que estas políticas construyen, y el impacto de estas en la comunidad y su opinión al respecto, entre otros aspectos, cuestiones que desde una mirada disciplinar la antropología ha problematizado y que esta investigación no desconoce (ver Shore 2010).
} 
abordadas en esta investigación. La muestra quedó conformada por funcionarios y ex funcionarios del área de cultura de la Municipalidad de Olavarría e investigadores y especialistas en patrimonio local. Las entrevistas se llevaron a cabo de manera presencial y virtual durante los meses de febrero de 2020 a febrero de 2021 y se realizaron siguiendo un guión flexible integrado por preguntas primarias y exploratorias específico para cada uno de los grupos de la muestra (Corbetta 2007). También se utilizó a la prensa gráfica local como fuente complementaria (Duverger 1981) para retomar la voz de algunos actores entrevistados en ellas o para reconstruir hechos o circunstancias del pasado detectados en las entrevistas.

Finalmente, es menester señalar que el trabajo aquí presentado forma parte de los resultados producidos en el marco de una tesis doctoral desarrollada por la autora, titulada "Sustentabilidad Sociocultural del Patrimonio urbano de la ciudad de Olavarría, Provincia de Buenos Aires, desde la década de 1980 hasta la actualidad". En este sentido, debido a las limitaciones en la extensión que el presente artículo tiene, algunas nociones aquí presentadas son brevemente desarrolladas.

\section{Contexto en el que se enmarcan las políticas culturales locales: la normativa nacional y provincial}

\section{Normativa nacional}

La regulación del patrimonio natural y cultural fue incorporada a la Constitución Nacional argentina en 1994. En ella se establece que las autoridades establecerán premisas para la preservación del patrimonio natural y cultural y se especifica que "corresponde a la Nación dictar las normas que contengan los presupuestos mínimos de protección, y a las provincias, las necesarias para complementarlas, sin que aquellas alteren las jurisdicciones locales" (art. 41). Es decir que el Estado Nacional debe dictar las "leyes marco" o de principios mínimos que luego son complementadas por las normas provinciales (Endere 2000). Si bien aún no se ha sancionado una ley de presupuestos mínimos del patrimonio cultural que sirva de base a las provincias para dictar sus propias leyes, existen normas nacionales que refieren a distintos tipos de patrimonio y que conforman el marco regulatorio general.

La protección legal del patrimonio en Argentina otorga un estatus jurídico diferencial a las distintas categorías de bienes culturales. Los yacimientos arqueológicos y paleontológicos pertenecen al dominio público del Estado desde el momento de su descubrimiento, lo que significa que son inenajenables, inembargables e imprescriptibles (ver art. 235 inc. h y art. 237 del Código Civil y Comercial). Los demás bienes culturales pueden ser de dominio público o privado y, para poder ser protegidos por el Estado, se debe dictar una declaratoria nacional, provincial o municipal, que debe emanar de los respectivos cuerpos legislativos. Aunque este tipo de declaratorias no altera la titularidad del bien, a menos que se disponga de su expropiación por ley, suelen prever diferentes medidas restrictivas del dominio para proteger el bien (Endere y Colombato 2017).

En lo que respecta a las leyes nacionales que protegen el patrimonio cabe destacar la Ley de Patrimonio Histórico y Artístico No 12.665 (modificada en 2015 por la Ley $N^{\circ} 27.103$ y el Decreto Reglamentario № 2.525), cuya autoridad de aplicación es la Comisión Nacional de Monumentos, de Lugares y de Bienes Históricos. Entre sus funciones está la de "ejercer la superintendencia inmediata sobre monumentos, lugares y bienes históricos nacionales y demás bienes protegidos (...) en concurrencia con las respectivas autoridades locales, cuando se trate de monumentos, lugares y bienes del dominio provincial o municipal" (art.1). Esta Comisión tiene además la potestad de proponer los bienes a declarar y de "establecer, revisar y actualizar los criterios y pautas de selección, clasificación y valoración". Otra norma relevante es la Ley Nacional de Protección del Patrimonio Arqueológico y Paleontológico $N^{\circ} 25.743$ de 2003 que regula de manera específica su preservación, investigación y adopta medidas contra su tráfico ilícito. Dentro del marco legal nacional se deben considerar también las convenciones internacionales que protegen el patrimonio cultural y natural y que fueron ratificadas por la República Argentina, como por ejemplo la Convención para la Protección del Patrimonio Natural y Cultural (París 1972) y la Convención para la Salvaguardia del Patrimonio Cultural Inmaterial (París 2003), entre otras ${ }^{3}$. También existe un gran compendio de cartas y recomendaciones emanadas de organizaciones internacionales especializadas en el patrimonio cultural, como UNESCO e ICOMOS (Consejo Internacional de Monumentos y Sitios), las cuales son consideradas como normas de soft law en nuestro sistema legal (Levrand y Endere 2020), vale decir, como acuerdos no legalmente vinculantes.

\section{Normativa provincial}

La Constitución Nacional establece que:

"esta Constitución, las leyes de la Nación que en su consecuencia se dicten por el Congreso y los tratados con las potencias extranjeras son la ley suprema de la Nación; y las autoridades de cada provincia están obligadas a conformarse a ella, no obstante cualquier disposición en contrario que contengan las leyes o constituciones provinciales" (art. 31).

Esto implica que lo que en ella se prescriba para cada materia, se constituye en una referencia y mandato para las leyes provinciales específicas.

3 Se debe destacar que, acorde a la Constitución Nacional, los tratados firmados con las demás naciones o con las organizaciones internacionales "tienen jerarquía superior a las leyes" (art. 75 inc. 22 primer párrafo). 
En lo que respecta a la provincia de Buenos Aires, su Constitución reformada en 1994 establece que la provincia debe garantizar el derecho a participar en la defensa del ambiente y de los recursos naturales y culturales mediante la preservación, el enriquecimiento y la difusión del patrimonio (art. 28). Declara que "la cultura y la educación constituyen derechos humanos fundamentales" (art. 198) y que la provincia "fomenta la investigación científica" y la "difusión de los conocimientos y datos culturales mediante la implementación de sistemas adecuados de información" (art. 43), también se "compromete a preservar, enriquecer, y difundir su patrimonio cultural, histórico, arquitectónico, arqueológico y urbanístico, y a proteger sus instituciones, así como a desarrollar políticas orientadas a rescatar, investigar y difundir las manifestaciones culturales" (art. 44).

A nivel provincial el patrimonio cultural es regulado por la Ley No 10.419, promulgada en 1986. En la actualidad, la autoridad de aplicación es la Dirección Provincial de Patrimonio Cultural, dependiente del Ministerio de la Producción, Ciencia e Innovación Tecnológica, que se debe encargar de "la planificación, ejecución y control de las políticas culturales de conservación y preservación de los bienes muebles o inmuebles declarados como bienes del patrimonio cultural" (art. 2). Acorde a la ley, pueden ser objeto de declaratoria los bienes muebles o inmuebles, incluyendo entre estos últimos a los "sitios, lugares o inmuebles (...) que se consideren de valor testimonial o de esencial importancia para la historia, arqueología, arte, antropología, paleontología, arquitectura, urbanismo, tecnología, ciencia, así como su entorno natural o paisajístico" (art. 7 inc. f). Dentro de su texto incorpora restricciones al dominio (art. 12).

En el marco de esta ley, el partido de Olavarría cuenta con un Monumento Histórico Provincial y Patrimonio Cultural de la provincia de Buenos Aires, declarado en 2002 mediante la Ley $N^{\circ} 12.966$, que corresponde al sitio del casco viejo del predio rural Monte Peloni, un centro de detención clandestino durante la última dictadura militar (Chaparro y Curtoni 2019).

Competencias municipales sobre el patrimonio cultural Como paso previo al análisis de la normativa y las políticas del Partido de Olavarría referidas al patrimonio cultural es necesario realizar algunas precisiones sobre las competencias -la capacidad de actuar- que tienen los municipios bonaerenses. La capacidad legal deviene como "resultado del balance entre el grado de autonomía municipal que reconoce la provincia, las competencias que establecen la constitución provincial y, de corresponder, las leyes orgánicas u otras leyes" (Endere e Iturburu 2010:11), dentro del marco general de autonomía municipal reconocido en el art. 123 de la Constitución Nacional. En la provincia de Buenos Aires se da la particularidad de la falta de cumplimiento de esta cláusula constitucional debido a que la carta magna provincial no consagra la autonomía municipal. De este modo, la competencia municipal en materia de patrimonio cultural se circunscribe a lo establecido en los inc. 4 y 6 del art. 192 de la Constitución Provincial, y en los arts. 25, 27 inc. 3 y concordantes de la Ley Orgánica de las Municipalidades ${ }^{4}$ (Endere e Iturburu 2010).

El cercenamiento de la autonomía municipal en los municipios bonaerenses por medio de la Constitución Provincial no impide que, por otras vías, se les reconozcan ciertas competencias sobre algunos componentes del patrimonio cultural. Al respecto, pueden hacer uso de la acción de amparo para la defensa de derechos de cuarta categoría (dentro de los cuales se considera al patrimonio cultural), más allá de la competencia concurrente de las administraciones nacional, provincial y municipal en materia de poder de policía vinculado a la obligación del Estado de "proveer a la preservación del patrimonio natural y cultural" (Endere e Iturburu 2010: 26). Como señalan estas autoras, "la regla es la coordinación aunque suele ser difícil dilucidar quién debe actuar ante un caso concreto" (2010: 26). A título de ejemplo, en materia de preservación edilicia, se debe considerar cuál es el bien jurídico a tutelar y si existe competencia municipal; así, si lo que se tutela son las fachadas o frentes de edificios de valor histórico, arquitectónico, cultural o comunitario, el Estado puede y debe intervenir por estar en juego un interés público. El Municipio es competente en la medida que se trate de "un bien colectivo de disfrute público" pero "si la restricción al dominio privado impide el uso normal del inmueble y se carece del consentimiento del titular, debe procederse a la expropiación" (2010: 26), acción que excede las competencias municipales porque se requiere de una ley provincial. En este sentido, las autoras han identificado antecedentes judiciales donde se ha reconocido la legitimidad de los municipios de actuar en defensa de los derechos de sus ciudadanos para proteger el derecho colectivo o difuso al patrimonio cultural de una ciudad.

\section{El Partido de Olavarría}

El partido de Olavarría se ubica en el centro de la provincia de Buenos Aires, República Argentina (Figura 1). Cuenta con su ciudad cabecera, la ciudad de Olavarría, doce localidades y diez parajes rurales ${ }^{5}$. Hacia 2010 contaba

\footnotetext{
4 Art. 25: "Las ordenanzas deberán responder a los conceptos de ornato, sanidad, asistencia social, seguridad, moralidad, cultura, educación, protección, fomento, conservación y demás estimaciones encuadradas en su competencia constitucional que coordinen con las atribuciones provinciales y nacionales". Art. 27: "Corresponde a la función deliberativa municipal reglamentar: (...) 3.- La conservación de monumentos, paisajes y valores locales de interés tradicional, turístico e histórico. (Decreto-ley 6769/1958 Ley Orgánica de las Municipalidades de la Provincia de Buenos Aires).

5 Las localidades Sierras Bayas, Loma Negra, Sierra Chica, Hinojo, Colonia Hinojo, Colonia San Miguel, Villa Mi Serranía, Santa Luisa, Colonia Nievas se ubican en las cercanías de la ciudad de Olavarría desde el noreste hasta el suroeste, mientras que Espigas, Recalde, Blanca Grande se ubican hacia el norte y oeste de la ciudad, en los límites con los partidos de Bolívar y Tapalqué. En el partido también
} 


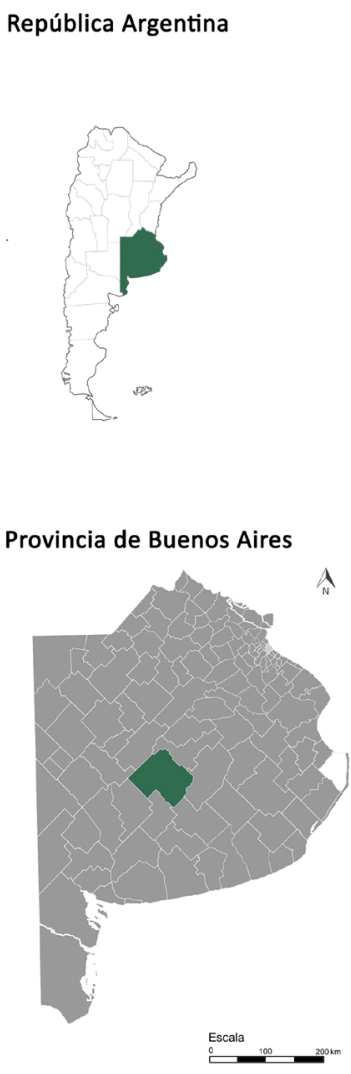

\section{Partido de Olavarría}

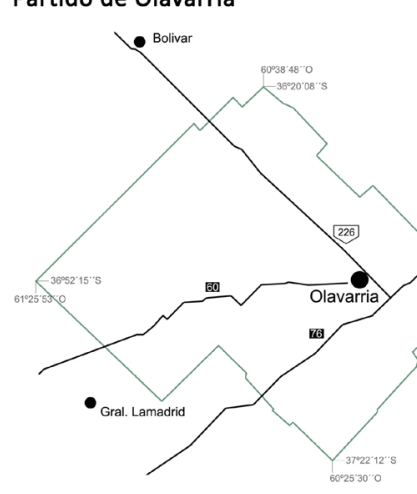

Ciudad de Olavarría y cercanías

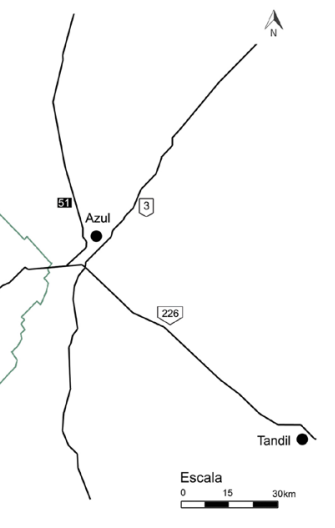

A

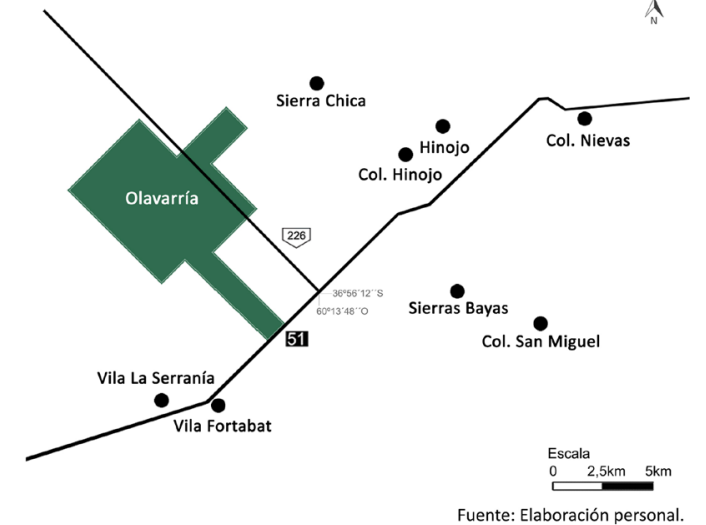

Figura 1. Localización del Partido de Olavarría y la ciudad de Olavarría. Fuente: Elaboración personal.

Figure 1. Location of the Olavarria County and the city of Olavarría. Source: Personal elaboration.

con 112.534 habitantes (INDEC 2010); la proyección a 2020 elevaba esta cifra a $120.154^{6}$. El 80,3\% de su población se concentra en la ciudad de Olavarría, ubicada en el este del partido con 89.712 habitantes (INDEC 2010), lo que la constituye en una ciudad intermedia menor (Di Nucci y Linares 2016).

Como todo espacio geográfico, el partido de Olavarría es parte de un territorio que da cuenta de las sucesivas modificaciones experimentadas. El poblamiento humano en la provincia de Buenos Aires tiene una antigüedad de aproximadamente 12.000 años A.C. ${ }^{7}$, con la llegada de bandas de cazadores-recolectores que alternaban entre la sierra y la costa, aprovechando de manera estacional diferentes recursos naturales (Politis 2012). Con la llegada de los españoles en el siglo XVI y la incorporación del ganado se transformó significativamente la vida y la economía de las poblaciones indígenas (Mandrini y Ortelli 1992). A mediados del siglo XVIII, el centro bonaerense fue escenario de una importante migración mapuche, pueblo que se integró a los serranos que la habitaban anteriormente; ello contribuyó a la formación de cacicazgos de creciente poderío económico y social que se sostuvieron hasta el siglo XIX (Ferrer y Pedrotta

se emplazan diez parajes rurales: Teniente Coronel Miñana, Durañona, Iturregui, La Providencia, Mapis, Cerro Sotuyo, Muñoz, Colonia Las Carmelitas, Pourtalé, Rocha, Villa Mónica.

6 Fuente: https://www.indec.gob.ar/indec/web/Nivel4-Tema-2-24-119. 7 Los fechados más antiguos datados en la región arrojan una antigüedad máxima de 14.064 años calibrados antes del presente (Politis et al. 2016).
2006, Pedrotta 2016). Durante este período, en el actual territorio del partido de Olavarría, funcionaba la feria comercial del Cayrú en la cual los indígenas intercambiaban productos entre sí y con la sociedad "blanca" (Pedrotta 2016).

El siglo XIX estuvo signado por el avance de militares y colonos "blancos" al sur del río Salado; se sucedieron entonces la fundación de fortines, pueblos, así como el establecimiento de estancias y pulperías. Durante el gobierno de Juan Manuel de Rosas se fundó el Fuerte Blanca Grande (1828) y se instalaron las tribus de Catriel y Cachul, considerados "indios amigos" por su condición de aliados del gobierno bonaerense (Langiano et al. 2009). Luego de la caída de Rosas (1852) comenzó una etapa de lucha por el control de los territorios y en ese contexto, entre 1855 y $1856^{\circ}$, se produjo una primera y fracasada fundación del poblado de Olavarría. Como puede observarse, su génesis se enmarca en el proceso de creación de fuertes y fortines militares que constituyeron la llamada "línea de frontera" en la avanzada sobre los territorios ocupados por los grupos indígenas. En 1863 se instaló el Fortín de las Puntas del Arroyo Tapalqué dando origen a la actual ciudad de Olavarría (Sassone 1981).

8 El 30 de mayo de 1855 se produjo el Combate de Sierra Chica durante el cual se intentó expulsar de la Frontera Sud a los caciques Catriel y Cachul. Sin embargo, las tribus indígenas, con la ayuda del "Cacique de las Pampas" Calfucurá, triunfaron y mantuvieron el dominio de las tierras. Un nuevo intento de avance de la frontera tuvo lugar el 29 de octubre de 1856, en el Combate de San Jacinto, en el que las tribus comandadas por los tres caciques volvieron a imponerse sobre el ejército criollo. 
El "Pueblo de Olavarría" fue creado por Decreto Provincial el 25 de noviembre de 1867. En 1877 se determinó la mensura de la traza y el ejido del pueblo (Arenas et al. 1967). Para entonces, ya se había producido la derrota definitiva y la expulsión de las tribus indígenas de su territorio. El 25 de octubre de 1878 se declaró al pueblo de Olavarría como cabecera del partido y, un año después, ya se habían establecido sus límites; finalmente, el 10 de enero de 1908, fue elevada al rango de ciudad. Para 1879 el partido era un mosaico multicultural, ya que vivían 403 familias, siendo más de dos tercios de ella inmigrantes (Arenas et al. 1967).

En las décadas de 1880 y 1890 se construyó el ferrocarril (del Sud) que extendió sus ramales por toda la región; alrededor de las estaciones florecieron decenas de pequeñas localidades -como Hinojo- y colonias de inmigrantes. En el partido se destacan Colonia Nievas, Colonia Hinojo y Colonia San Miguel, mayoritariamente pobladas por ruso-alemanes que se instalaron a partir de 1877 mediante la cesión de tierras (Sassone 1981). El emplazamiento de poblados rurales (e.g. Recalde, Santa Luisa, Espigas, entre otros) respondió al furor agro-ganadero pero también, desde la instalación de la primera fábrica cementera en 1917, se desarrollaron nuevas industrias -la picapedrera, la láctea, la harinera y la metalúrgica- que le otorgaron a la región un particular perfil industrial (Paz 2009). El crecimiento de la industria del cemento contribuyó a incrementar la inmigración europea de mano de obra calificada desde fines del siglo XIX hasta la primera mitad del XX, así como al crecimiento de localidades asociadas a la actividad minera, entre las que se destacan Sierra Chica, Loma Negra y Sierras Bayas. Posteriormente, desde 1950, se incrementaron las inmigraciones provenientes de países latinoamericanos, principalmente de Bolivia. Así, Olavarría se convirtió en el destino final de numerosas corrientes migratorias provenientes de Europa y Latinoamérica (Mariano 2013).

\section{Las políticas públicas culturales del Municipio de Olavarría}

Durante el período seleccionado, a nivel local, en 1983 comenzó el primer mandato de Helios Eseverri, dando inicio a lo que luego se denominó el "eseverrismo", el grupo político que gobernó siete de los diez mandatos que comprende el período analizado. En efecto, Helios Eseverri (por el partido Unión Cívica Radical-UCR y desde 2005 por el Frente para la Victoria) gobernó durante cinco períodos desde 1983 hasta septiembre de 2007, con una única alternancia entre 1987 y 1991, a cargo de su oponente Juan Manuel García, del Partido Justicialista. Helios Eseverri falleció hacia finales de su último mandato y fue reemplazado por un período de cuatro meses por el presidente del Concejo Deliberante Julio Héctor Alem. En 2007 fue electo su hijo, José María Eseverri, quien gobernó durante dos períodos, como representante del Frente para la Victoria. En las elecciones de 2015 perdió la intendencia a manos de Ezequiel Galli, perteneciente a Propuesta Republicana (PRO), marcando un quiebre de casi treinta años de gestión eseverrista. Galli estuvo a cargo de la intendencia hasta 2019 cuando fue reelecto para el período 2019-2023.

Las diferentes políticas culturales se describen en orden cronológico, divididas en tres períodos (ver Figura 2). Estos se conforman acorde al agrupamiento de los períodos de gobierno bajo el mismo intendente, dando como resultado, un primer período de 1983 a 2007, donde se analizan los cinco mandatos llevados adelante por Helios Eseverri (y se incluye el mandato de Juan Manuel García durante 1987-1991), un segundo período que incluye las dos intendencias de José María Eseverri, y un tercer período que analiza el primer mandato de Ezequiel Galli, iniciado en 2015, y parte del segundo que se prolonga hasta el año 2023. Debido a la extensión del presente trabajo, la normativa emanada de dichas políticas públicas será mencionada mas no desarrollada.

De la avidez cultural a la consolidación de las políticas culturales (1983-2007)

Con el retorno de la democracia, la etapa comprendida entre 1983 y 1987, se caracterizó por la efervescencia ciudadana y una gran "avidez" por generar propuestas culturales por parte de la comunidad y de la gestión municipal: "la apertura de la democracia fue tan grande que todo el mundo quería hacer algo" (María Irene Blanco ${ }^{9}$, entrevista, 20/02/2020). Durante el primer mandato de Helios Eseverri se llevó adelante un proceso de reconstrucción de las estructuras que daban soporte institucional a las diferentes expresiones culturales. A las actividades y espacios preexistentes -como la Escuela de Cerámica, la Escuela de Orfebrería, el Museo Dámaso Arce (MDA en adelante) y el Etnográfico Dámaso Arce (MEDA en adelante)- se sumaron otras como el Taller Literario. En lo referente a las expresiones musicales, ya existía el Conservatorio de Música Municipal al que se sumó una orquesta de cuerdas, una orquesta sinfónica y la banda de música. Asimismo, a los tradicionales desfiles cívico-militares que se realizaban en fechas patrias, se sumaron otros eventos culturales al aire libre. En Olavarría, "La Plaza quiere vivir" era un programa que consistía en espectáculos públicos que se realizaban los días domingos en la plaza central; "Un Aplauso al asador", fue una propuesta que se mantuvo durante todo el período analizado y consiste en el despliegue anual de parrilladas montadas en un parque por distintas instituciones de bien público, acompañadas de actividades recreativas, con el propósito para recaudar fondos; los Corsos de Carnaval incluían el desfile de comparsas por la Avenida Del Valle, una de las principales vías del ejido que delimita el centro urbano. A ellos se sumaron distintos espectáculos sobre las márgenes del Arroyo Tapalqué, arroyo que divide a la ciudad de SO a NE.

9 Directora de Cultura y Educación durante 1983-1987 (durante este período la Dirección de Cultura dependía de la Secretaría de Gobierno). 
Durante este mandato, el gobierno municipal no se ocupó de cuestiones vinculadas al patrimonio arquitectónico: "se dejó un poco de lado" y "la mirada del gobierno fue externa" al tema (María Irene Blanco, entrevista, 20/02/2020). Sin embargo, surgieron inquietudes en relación con este patrimonio, organizadas en torno al trabajo voluntario de arquitectos preocupados por la preservación, que luego conformaron el Grupo Patrimonio Arquitectónico de Olavarría (Arabito 2009). En contraposición, el patrimonio mueble de la ciudad se consolidó a partir de la revalorización de la importante colección del MDA y del papel preponderante que este adquirió en la vida cultural (Chaparro 2017).

Hacia 1987, con el comienzo de la debacle económica que terminó en la hiperinflación y la entrega anticipada del gobierno de Raúl Alfonsín en 1989, las primeras áreas municipales en las que se hicieron recortes fueron aquellas destinadas a la cultura. En ese contexto, mermaron las exposiciones y los espectáculos foráneos.

Entre 1987 y 1991, el mandato del gobierno peronista de Juan Manuel García Blanco se caracterizó por la ampliación y consolidación de las distintas estructuras que daban soporte a las actividades culturales. Se quintuplicó la planta destinada a cultura, reforzando el plantel de museos, teatro y escuelas municipales (Juan Waldemar Wally ${ }^{10}$, entrevista, 18/02/2020). Asimismo, se reconvirtieron actividades culturales ya instaladas en la sociedad, las que fueron modificadas para darle un carácter "más popular" (Juan Waldemar Wally, entrevista, 18/02/2020). Este fue el caso del evento "La Plaza quiere vivir" que mutó a "El Pueblo va a su plaza", que si bien mantuvo el formato de espectáculo dominguero y estival, adicionó la organización de bailes populares al concluir los números musicales y se relocalizó del centro de la plaza a la calle Rivadavia, frente al Teatro Municipal, en donde se colocaron sillas para los asistentes. Lo mismo sucedió con "Un Aplauso al Asador", que se mantuvo pero en una nueva fecha en coincidencia con el "Día de la Tradición". Además de sostenerse el apoyo y la creación de diversas bandas y orquestas municipales, se incorporó a la agenda municipal el Festival $1^{\circ}$ de Mayo, una maratón que se despliega por las calles de la ciudad de Olavarría y es organizada por el municipio (Juan Waldemar Wally, entrevista, 18/02/2020). En los últimos años se modificó el nombre de este evento por el de "Vuelta al Municipio", que ya tuvo 31 ediciones.

Respecto de la protección del patrimonio, particularmente el arquitectónico, se promovió la Ordenanza N 763 en 1988. No obstante, la misma nunca fue reglamentada (Endere 2009).

A pesar de la ampliación de las políticas culturales iniciadas al comienzo del mandato, la crisis económica

10 Director de Cultura 1987-1991 y Subsecretario de Cultura y Educación 1992-2001. nacional de finales de 1980 significó una reducción del presupuesto destinado a Cultura (Juan Waldemar Wally, entrevista, 18/02/2020).

Durante los siguientes cuatro mandatos de Helios Eseverri (1991-2007) la Dirección de Cultura fue jerarquizada, pasando desde entonces a denominarse Subsecretaría de Cultura y Educación ${ }^{11}$. Gran parte de la política cultural de esta etapa estuvo enfocada en las localidades del partido, mediante la creación de una red de museos conformada por: el Museo Municipal de la Estación, fundado en 1994 en Sierra Chica, orientado a la historia minera del lugar; el Museo Municipal de los Alemanes del Volga "Ariel Cherico", en Colonia Hinojo, creado en 1998; el Museo Municipal de la Piedra "Emma Occhi", creado en 1999, también en Sierra Chica; y el Museo Municipal "Miguel Stoessel Müller", en Colonia San Miguel, conformado en el año 2000, orientado a recuperar la memoria de los Alemanes del Volga. Este proceso fue fortalecido por el desarrollo de actividades en estas nuevas sedes culturales, tales como la promoción de un ballet folclórico alemán o las clases de idioma alemán en Colonia Hinojo. Además de fomentar la autovaloración de la identidad y de la cultura de los descendientes de inmigrantes y de las villas obreras mineras, la creación de los museos en las localidades generó gran afluencia de la población de la ciudad de Olavarría, como forma de ocio. En esta etapa también se crearon las Escuelas Municipales de Artes Plásticas, Teatro, Danza y Música, que se sumaron a las preexistentes, y se creó un anexo de la Escuela de Cerámica con sede en Sierras Bayas. El impulso a la música estuvo a la altura de los restantes desarrollos: se reactivó en 1993 la Orquesta Sinfónica Municipal y se creó el Quinteto de Vientos Municipal12. Por último, se establecieron el Ballet Folclórico Municipal y el Ballet Iberodanza ${ }^{13}$. En palabras de la autoridad del área, durante los gobiernos de Helios Eseverri la política cultural "no se centró en traer artistas o exposiciones hacia la ciudad, sino en apoyar y potenciar a los artistas y conjuntos locales, promoviendo su proyección por fuera del partido de Olavarría" (Juan Waldemar Wally, entrevista, 18/02/2020).

La década de 1990 se caracterizó por la adopción de políticas públicas a favor de la revalorización del patrimonio tal como el financiamiento de excavaciones arqueológicas en el Fuerte Blanca Grande ${ }^{14}$. Cabe destacar,

11 En el 2001 volvió a modificarse la denominación del área: Subsecretaría de Cultura, Educación y Comunicación.

12 A estos conjuntos se le sumaban la Banda Mayor Municipal, que actuaba en actos oficiales, la Banda Infanto Juvenil, el Quinteto Municipal Típico Hermanos Rossi, el Cuarteto Popular, el Grupo Municipal Instrumental Sikus, el Grupo Municipal Nuevo Flamenco y la Orquesta Popular.

130tras fuentes: https://www.youtube.com/ watch?v=2016qb7hdDc\&t=11s

14 En 1988 el Municipio apoyó la creación de la Facultad de Ciencias Sociales de la Universidad Nacional del Centro de la Provincia de Buenos Aires, que tiene las carreras de Licenciatura en Antropología con Orientación Social y con Orientación Arqueológica. La investigación del Fuerte estuvo a cargo de profesores y alumnos de dicha facultad. Las tareas investigativas realizadas en el sitio se declararon de interés 
además, la organización de actividades de promoción del patrimonio que fueron subsidiadas y auspiciadas por el municipio. A modo de ejemplo, en 1993 la municipalidad financió la Semana de la Paleontología en Olavarría, realizada en colaboración con la cátedra de Paleontología de la Facultad de Ciencias Sociales (UNICEN) dirigida por José Luis Prado. Durante ocho días se desarrollaron múltiples actividades, dirigidas a diferentes públicos, sobre todo el infantil, llegando a congregar una cantidad considerable de visitantes. El objetivo de esta actividad fue difundir y concientizar a la población sobre la riqueza paleontológica del Partido. También, como cooperación pública/privada, se financió parte del estudio sobre patrimonio arquitectónico desarrollado por el grupo Patrimonio Arquitectónico Olavarría, el cual consistió en un relevamiento de 177 inmuebles del partido realizado entre 1997 y 1998 (Arabito 2009). El interés sostenido de las autoridades municipales en la promoción de estudios sobre la historia local se evidencia en la aplicación de fondos y en el acompañamiento de estas y otras actividades similares ${ }^{15}$.

Respecto de la protección legal del patrimonio a nivel local, se sancionaron dos ordenanzas específicas. La primera de ellas, la Ordenanza N².031/96 para la Protección del Patrimonio Arqueológico y Paleontológico, estableció la obligación de efectuar evaluaciones de impacto arqueológico en contextos de obra; sin embargo, este mandato no se respeta porque nunca fue reglamentada. En tanto, la Ordenanza N² 2.316/98 para la Protección del Patrimonio Arquitectónico, posteriormente ampliada por la Ordenanza № 2.973/06, delimita un "área de interés arquitectónico patrimonial"16, ubicada en el sector céntrico de la ciudad de Olavarría, y se concentra en la preservación de fachadas de inmuebles considerados valiosos para el patrimonio local mediante la aplicación de restricciones y límites al dominio.

Durante esta etapa se sancionó también la Ordenanza $\mathrm{N}^{\circ}$ 2.108/96, que autorizó al municipio a adquirir y declarar como patrimonio histórico cultural a "La Galera", el automóvil de competición de Turismo de Carretera perteneciente a los hermanos Emiliozzi ${ }^{17}$. Además, se

municipal por Decreto Municipal N²885/92.

15 A título de ejemplo, se creó la Comisión Municipal de Estudios Históricos. Esta organizaba anualmente encuentros de historia local mediante la convocatoria a profesionales y amateurs. Asimismo, se continuó financiando la publicación de ETNIA, revista del Instituto de Investigaciones Antropológicas de Olavarría, hasta la primera década del nuevo milenio así como otras publicaciones vinculadas a la historia y el patrimonio olavarriense. También en 1993 financió la Semana de la Paleontología en Olavarría, realizada en colaboración con la cátedra de Paleontología de la Facultad de Ciencias Sociales (UNICEN).

16 Comprende al sector comprendido por las calles Cerrito, Necochea, 25 de Mayo y Coronel Suárez.

17 Los mismo son referentes de la historia del automovilismo local. Torcuato "Tito" Emiliozzi fue un mecánico y preparador de autos, inventor de "las válvulas a la cabeza" y, su hermano Dante, un piloto que participó en las carreras de Turismo Carretera (TC en adelante) entre las décadas de 1950 y 1960, cuando se corría en las calles de la propia ciudad. recibió la donación del cuadro original del General Manuel Belgrano, obra del pintor Francois Casimir Carbonier y se lo declaró patrimonio histórico cultural mediante la Ordenanza No 2.034/96.

Asimismo, se refaccionó el interior del Teatro Municipal, el cual había sufrido grandes deterioros durante las inundaciones que asolaron a la ciudad de Olavarría en 1980 y 1985 . Este espacio se jerarquizó en su función cultural mediante la creación de la Dirección del Teatro Municipal. Además, se compró y restauró lo que comenzó a denominarse Palacio Belgrano, la antigua sede del Correo Argentino, y se reacondicionó el Palacio San Martín, sede del gobierno municipal.

La cultura se expande como parte de la agenda política (2007-2015)

Este período se caracteriza por una intensa y sostenida incorporación de la cultura dentro de la plataforma política al ser considerada como "un valor estratégico en el desarrollo de la ciudad" (Eduardo Rodríguez ${ }^{18}$, entrevista, 22/06/2020). En consonancia con esta definición política, desde el año 2011, la Subsecretaría de Cultura y Educación pasó a formar parte de la Secretaría de Desarrollo Social. La incorporación de las áreas de Deporte y Cultura reflejó la opción por el desarrollo integral de las comunidades, buscando una cultura inclusiva que excediera al centro de la ciudad (Diego Lurbe ${ }^{19}$, entrevista, 22/06/2020). Al respecto, el intendente José María Eseverri declaraba que se buscaba "asumir la cultura desde la diversidad y como constructora de ciudadanía. La cultura nos permite ser mejores" (Diario El Popular, 14/14/2007, En Cultura y Educación también se hará Turismo). Esta decisión se reflejó en el aumento de la inversión del presupuesto municipal en Cultura, el cual se duplicó respecto del período anterior, alcanzando un $6,5 \%$ del presupuesto municipal (Eduardo Rodríguez, entrevista, 22/06/2020).

Durante los dos mandatos de gobierno se continuó con la política del período precedente en lo relativo a la creación de museos. La red de museos de las localidades integró a cinco nuevos, cuatro municipales y uno de carácter público-privado, alcanzando un total de nueve. A los cuatro museos creados en el período anterior se sumaron: el Museo Municipal de Espigas (2010), el Museo Municipal de Hinojo (2011), el Museo de Mapis (2012) y el Museo Hogar Municipal de Loma Negra (2014). También se creó el Museo de Sitio La Calera, en uno de los primeros hornos de cal de la localidad de Sierras Bayas, que se hallaba en desuso ${ }^{20}$. En 2013, se conformó en la ciudad de Olavarría el Museo Municipal de los Hermanos Emiliozzi (MHE en adelante) en el edificio donde se encontraba el taller y el salón comercial, el cual había sido adquirido

18 Subsecretario de Cultura, Educación y Comunicación entre 20012006 y Subsecretario de Cultura, Educación y Turismo 2007-2009.

19 Subsecretario de Cultura, Educación, y Turismo 2009-2011 y Subsecretario de Cultura y Educación 2011-2015.

20 Actualmente este último museo está cerrado. 
por el municipio en 2005. En el marco de estas políticas culturales se realizaron, en 2011, estudios de público mediante la utilización de indicadores, pero los mismos nunca fueron tabulados (Agustina Marino ${ }^{21}$, entrevista, 21/02/2020). También se construyó un nuevo edificio para el Museo de Ciencias, que se ubicó en el Bioparque La Máxima (ex zoológico de la ciudad), y se trasladaron las colecciones del MEDA a la antigua casa que se ubica en el mismo predio (Chaparro 2017)22. Por último, se construyó el Corsódromo Municipal, ubicado entre las calles Junín, Guisasola, San Martín y Sargento Cabral, sobre el predio del ex ferrocarril "El Provincial".

En lo referente a la educación artística, se mantuvieron las escuelas municipales consolidadas en el período anterior, a lo que se sumó la municipalización del "Programa de Integración por el Arte", antes financiado por el gobierno provincial y que incluía clases de teatro, danza, música, plástica, narración oral y braille para niños y jóvenes con capacidades diferentes.

Al calendario de celebraciones se sumaron la Fiesta de Olavarría, para el aniversario de la ciudad, la Feria del Libro, la Muestra de Cine Nacional "Lucas Demare" (que llegó hasta su $18^{\circ}$ edición) ${ }^{23}$ (Diario El Popular, 14/09/2011, Se hizo el lanzamiento de la Muestra de Cine Nacional "Lucas Demare"), el Festival Internacional de Cortos de Olavarría (que alcanzó su $6^{\circ}$ edición en 2013), el Encuentro de Teatro Independiente (2012), entre otras fiestas organizadas en Olavarría y las localidades.

También, en "apoyo a los centros de cultura no estatales", se sancionó la Ordenanza N³.822/15 de Registro de Espacios Culturales no Estatales del Partido de Olavarría, la cual permite registrar tales espacios y eximirlos de ciertas tasas municipales, en especial las que gravaban el espacio físico o los espectáculos (Eduardo Rodríguez, entrevista, 22/06/2020).

En términos de políticas patrimoniales, se realizaron grandes inversiones para la restauración en algunos edificios municipales. Entre los trabajos más importantes de este período, a nivel cultural y patrimonial, cabe destacar la restauración del antiguo Hogar de Niñas San José, construido en 1913 por la Sociedad de Beneficencia de Olavarría y cedido en comodato por 25 años a la Municipalidad a cambio de su restauración ${ }^{24}$. Ello permitió la creación del Centro Cultural Municipal Hogar San José "bajo el concepto de igualar oportunidades a través de la cultura" (Agustina Marino, entrevista, 21/02/2020), lo que exigió adaptar el espacio de exposición a los

21 Funcionaria del área de cultura de la Municipalidad de Olavarría desde 2011 y Subsecretaria de Cultura y Educación desde 2018 a 2021. 22 En este contexto, se auspició y financió la muestra “Olavarría antes de Olavarría" (Endere et al. 2010) en el Museo de las Ciencias en sus diferentes ediciones en 2010 y en 2014.

23 Este festival se realizó de 1980 a 1984; posteriormente, se retomó en 2002 y se sostuvo hasta el año 2015.

24 Este edificio había sido severamente dañado durante las inundaciones de 1980 y 1985, ya que se ubica frente al Arroyo Tapalqué. requerimientos de determinadas obras de arte. Ello permitió el acceso a un circuito de obras destinadas a espacios o ciudades más grandes y se logró traer exposiciones de artistas internacionales tales como Dalí, Picasso y Miguel de Molina, y artistas nacionales como Quino, Liniers, Milo Locket y Marcos López, entre otros (Agustina Marino, entrevista, 21/02/2020). También se creó la Casa del Bicentenario en 2010, sobre la base del edificio del antiguo Balneario Municipal. De la remodelación emergió una segunda plaza teatral con capacidad para 200 personas, destinadas a espectáculos más íntimos ${ }^{25}$.

El MDA también fue modificado; se construyó un depósito de conservación para la colección permanente con temperatura y humedad controlada, y se modificaron las salas de exposición para tener un formato "mucho más amplio, luminosos y moderno" (Diego Lurbe, entrevista, 22/06/2020). También se modernizó el sistema de sonido del Teatro Municipal que en la actualidad es uno "de los más avanzados del país" (Diego Lurbe, entrevista, 22/06/2020).

En este período se realizaron dos importantes propuestas que finalmente no prosperaron. Por un lado, se presentó un "Anteproyecto de Ordenanza General de Protección del Patrimonio Cultural y Natural, Arquitectónico Urbano y Rural, Arqueológico y Paleontológico del Partido de Olavarría", elaborado en 2009 por María Luz Endere y Mario Arabito, en el marco de un estudio financiado por el gobierno municipal; sin embargo, el proyecto nunca fue presentado por el Ejecutivo para su consideración en el Concejo Deliberante local. Por el otro, se presentó la propuesta de declaratoria como monumento histórico nacional del edificio de la Escuela Normal José Manuel Estrada, la que fue ratificada en plenario de la Comisión Nacional de Museos, Monumentos y Lugares Históricos en agosto de 2012. No obstante, el proyecto de ley perdió estado parlamentario en febrero de 2015 , constituyéndose en el único bien de la ciudad de Olavarría en alcanzar esa instancia (Cantar 2018).

La cultura en pausa (2015-2020)

El cambio de gobierno, tras la asunción de Ezequiel Galli, derivó en continuidades pero también rupturas de las políticas culturales en general, y de las patrimoniales, en particular.

En la actualidad la Subsecretaría de Cultura y Educación está conformada por cinco direcciones: la Dirección del Centro Cultural, la Dirección de Cultura, la Dirección de Educación, la Dirección del Bioparque "La Máxima", y la Dirección del "Teatro Municipal" y "Casa del Bicentenario". También tiene jerarquía de dirección el Centro Cultural San José, espacio con seis salas de exposición que "se ha posicionado a nivel regional y provincial" (Agustina Marino, entrevista, 21/02/2020).

25 En contraposición, el Teatro Municipal cuenta con 1.064 plazas. 
Recientemente se ha creado el DEAC (Departamento de Extensión y Acción Cultural), cuya función es la de servir de "nexo" entre la Subsecretaría e Instituciones Educativas de la comunidad (escuelas, universidades, profesorados) (Agustina Marino, entrevista, 21/02/2020). Entre las rupturas, cabe destacar la disolución de la Dirección de Patrimonio, Museos y Archivos (que funcionó de 2015 a 2019), la cual se ocupaba fundamentalmente del manejo de museos y del Archivo Histórico Municipal.

Con dependencia de la Dirección de Educación, se sostienen las ocho escuelas municipales consolidadas en el período anterior: Escuela Municipal de Cerámica, y Escuela Municipal de Artes Plásticas "Leopoldo Bocazzi", con sede cada una en Olavarría y en Sierras Bayas; Escuela Municipal de Orfebrería y Artesanías Tradicionales "Maestro Armando Ferreira", Escuela Municipal de Música "Hermanos Rossi", Escuela Municipal de Danza y Escuela Municipal de Teatro. También se mantienen la Escuela Municipal literaria "Alfonsina", la Escuela Municipal de Ajedrez y la Escuela Municipal de Arte integrado, la que realiza talleres en diferentes espacios culturales y educativos de la ciudad. Además de la actividad desplegada en dichas escuelas, se realizan actividades y se organizan talleres en barrios y localidades del partido.

Los eventos culturales se rigen por un calendario cultural anual que es aprobado por el Concejo Deliberante. Este oficia como "esqueleto" de las celebraciones periódicas, aunque se admite la incorporación de otras que no tienen una frecuencia anual (Agustina Marino, entrevista, 21/02/2020). El calendario incluye las fiestas patronales, las fiestas de aniversario de la ciudad y de cada localidad, Carnavales, la "Fiesta del Día del Niño", "Un Aplauso al Asador", entre otras que son asumidas como "patrimonio intangible" por estar instaladas en el repertorio cultural de la ciudad. La gestión de estas actividades corresponde a la Dirección de Cultura. También se realiza el Festival de Cine Latinoamericano, que es un evento bianual, dependiente de la Dirección del Teatro y Casa del Bicentenario. La comunicación de los eventos y actividades depende de la Subsecretaría de Prensa y Comunicación, lo que se reconoce como una "gran falencia porque no tenemos ni agilidad ni muchas veces la decisión de poder comunicar algo que nos interesa" (Agustina Marino, entrevista, 21/02/2020). Recientemente algunas instituciones, como los museos, abrieron cuentas en redes sociales que gestionan de manera independiente de la Subsecretaría de Prensa.

En lo que respecta a la temática patrimonial, al inicio del período de gobierno en 2016, la Subsecretaría de Cultura y Educación convocó a referentes e investigadores del patrimonio olavarriense a efectos de definir los lineamientos de la gestión cultural en atención a las características y necesidades del patrimonio cultural. Los investigadores que asistieron a la reunión observaron que la entonces Subsecretaria de Cultura y Educación se mostró "sorprendida" por la variedad y cantidad de patrimonios identificados en Olavarría y constataron que "tenía un concepto bien reducido de cómo eran las problemáticas reales del patrimonio en la ciudad" (Mercedes Mariano ${ }^{26}$, entrevista, 18/02/2020). No obstante, a pesar del interés mostrado por la funcionaria, en comparación con el período anterior, algunas políticas aplicadas en favor del patrimonio perdieron continuidad; a título de ejemplo, se desestimó el proyecto de crear un museo en la Casa del Bicentenario con los restos arqueológicos encontrados en la excavación de uno de los pocos sitios arqueológicos del ejido de la ciudad, el Molino "La Clara", y se perdió o degradó gran parte de la cartelería indicativa del sendero de interpretación del patrimonio arqueológico en el Parque Mitre, sin que se desplegaran acciones para su conservación (Julio Merlo ${ }^{27}$, entrevista, 18/02/2020).

En general, se observó desfinanciamiento de la política cultural, cuestión que se refleja en la comparación de las partidas presupuestaria de los últimos años ${ }^{28}$. Esto derivó en una desarticulación en el área cultural ${ }^{29}$ y una disminución de la oferta cultural municipal.

El principal aporte de este período, en términos patrimoniales, fue la sanción de la Ordenanza Municipal N³.934/16 orientada a la "determinación, preservación, restauración, promoción, acrecentamiento y transmisión del Patrimonio Histórico Cultural del Municipio de Olavarría" (art. 1) la cual se constituye en una norma de protección patrimonial general.

Hacia el final del período analizado se reorientó la gestión del Centro Cultural San José con el propósito de consolidarlo como el espacio cultural principal de la ciudad. Esto marca una diferencia respecto a la política cultural de los primeros años porque, en palabras de su responsable, si bien desde el inicio del período el presupuesto para cultura fue recortado significativamente, en esa primera época "no hubo ni presupuesto ni mirada,

26 Doctora en Antropología Social, Investigadora y Docente de la universidad local (UNICEN), especialista en patrimonio inmaterial.

27 Doctor en Arqueología, Investigador y Docente de la UNICEN, especialista en patrimonio arqueológico.

28 La disminución del presupuesto municipal para el área de cultura del gobierno de turno se observa en la rendición de cuentas del año 2019 (Proyecto de Ordenanza, Expediente 2020-000052-140284, 05/05/2020, Honorable Concejo Deliberante), el presupuesto general para el año 2020 (Proyecto de Ordenanza, Expediente 2019-000436$138258,01 / 11 / 2019$, Honorable Concejo Deliberante) y el presupuesto proyectado para el año 2021, cuyo promedio ronda el 2,57\% sobre el presupuesto total, en contraste con las partidas presupuestarias del segundo período analizado en este trabajo, donde se llegó a "a tener en su momento un porcentaje, que es considerado muy alto, del 6,5\% del presupuesto municipal" (Eduardo Rodríguez, entrevista, 22/06/2020)

29 Por ejemplo, ciertos recursos humanos con formación específica en el área cultural fueron reasignados a otras funciones que no requerían de sus conocimientos. Asimismo, en 2019, con la renovación del mandato del actual gobierno municipal se disolvió la Dirección de Patrimonio Cultural, que había sido creada por la actual dirección de la Subsecretaría de Educación y Cultura. 


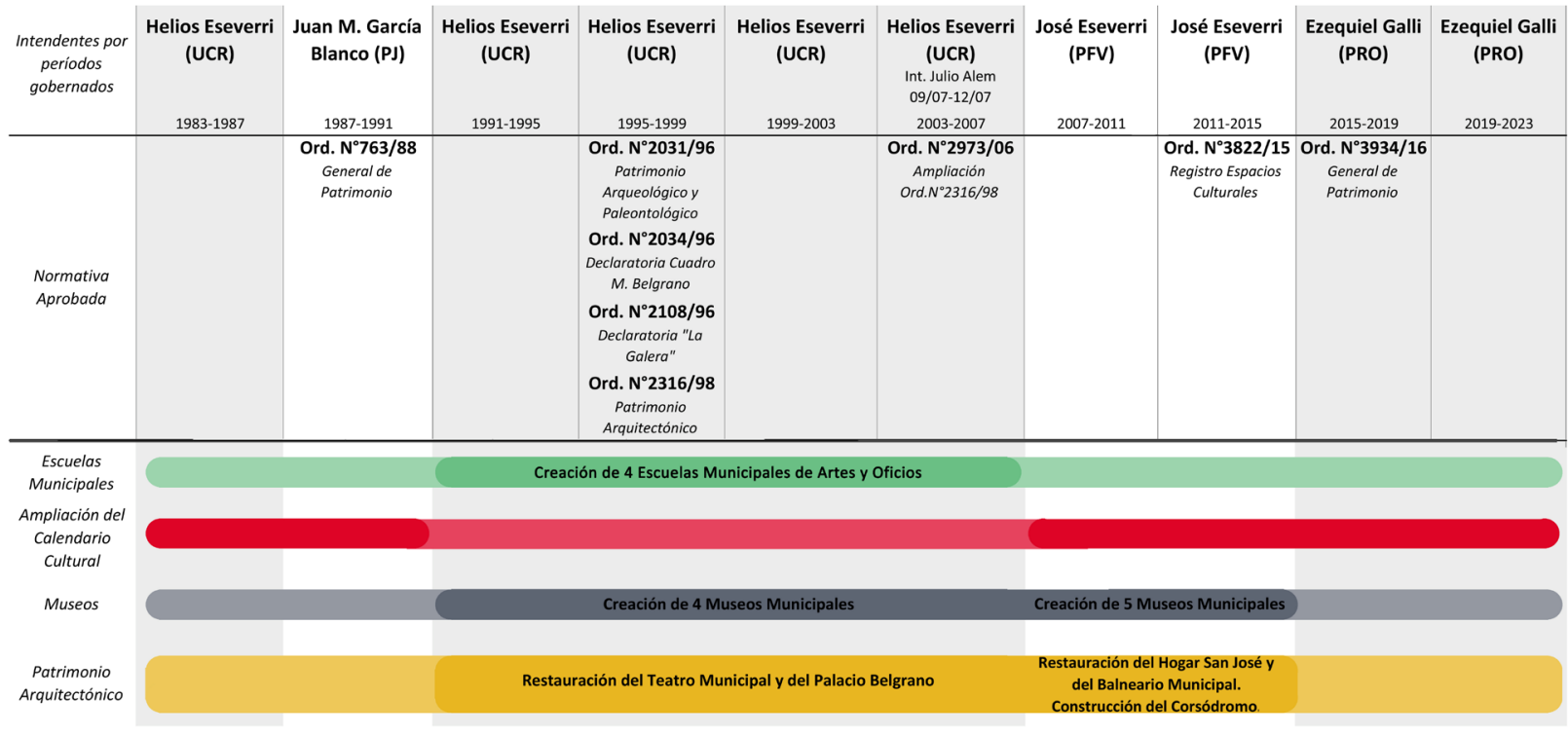

Figura 2. Síntesis de las normas locales y las principales políticas culturales implementadas en cada mandato de gobierno, para el período 1983-2020. Fuente: elaboración personal.

Figure 2. Synthesis of local regulations and the main cultural policies implemented in each government mandate, for the 1983-2020 period. Source: personal elaboration.

y ahora tenemos una mirada, ya iremos recuperando el presupuesto" (Agustina Marino, entrevista, 18/02/2020).

Por otro lado, aunque se expresaron intenciones de elaborarlo, el municipio no cuenta con un inventario patrimonial unificado que incluya todos los bienes culturales del partido y ; por el contrario, esta información se encuentra diseminada en diferentes instituciones y dependencias de la gestión municipal ${ }^{30}$. Vale aclarar que no todos esos inventarios son de acceso público.

Las políticas culturales de los tres períodos analizados se sintetizan en la Figura 2. En ella se relacionan los mandatos de cada intendente, las normas locales aprobadas y las políticas llevadas a cabo. El análisis de estas últimas se agrupó en cuatro conjuntos -escuelas municipales, calendario cultural, museos y patrimonio arquitectónico- considerando que estos concentran las principales acciones de gobierno orientadas a la cultura. Se resaltan con mayor intensidad de color los mandatos que realizaron algún aporte a alguno de estos cuatro conjuntos; la "ampliación del calendario cultural" se indica, pero no se detallan las propuestas incorporadas por razones de espacio.

\section{Consideraciones finales}

La política legislativa, expresada en leyes, decretos y ordenanzas, pone al descubierto el vínculo que existe

30 Algunos museos cuentan con sus propios inventarios; el Archivo Municipal dispone de un registro de monumentos realizado por el diario local "El Popular" en el año 2000, y las fiestas y celebraciones se registran en el calendario anual. entre el patrimonio y la sociedad en un momento dado, así como la concepción predominante de patrimonio y diversidad cultural (Levrand 2009). La normativa cultural procura regular y ordenar procesos a posteriori de su surgimiento, razón por la cual no logra abarcarlos o establece restricciones que no se adaptan a los procesos que ya están sucediendo en los territorios. Sin dudas, ello es aplicable al caso de Olavarría, donde también se observa la existencia de normas que lejos de constituirse en herramientas de gestión son meramente declarativas por su falta de reglamentación e instrumentación.

En paralelo, no se percibe una postura constante respecto de las políticas relativas a la gestión del patrimonio en el gobierno local en funciones, lo que se refleja en la aplicación aún limitada de la Ordenanza N 3.934/16, la de mayor alcance en términos de protección patrimonial. Entre las críticas más destacadas a esta ordenanza, se menciona que "nunca tuvo una incorporación de un catálogo formal bien hecho (...) y no hay un reglamento que diga qué modificaciones se permiten hacer. Asimismo, en el listado incorporado en la ordenanza, aparecen obras que no existen (ni existían al momento de su publicación)" (Mario Arabito ${ }^{31}$, entrevista, 20/02/2020). Estas críticas podrían ser replicadas para gran parte de las normas de protección patrimonial emanadas en el período, que no cuentan con reglamentación y su aplicación es limitada o nula.

En este sentido, aunque la sanción de la norma provee un marco de acción legal y sienta precedentes, su alcance

31 Arquitecto, especialista en el patrimonio arquitectónico del Partido de Olavarría. 
es escaso si los bienes que se intenta proteger no son identificados y, luego, protegidos y gestionados desde una mirada integral que aborde los significados que se les atribuyen. Asimismo, en la actualidad, se observa que las acciones desplegadas por el gobierno municipal siguen limitándose a determinados bienes que se encuentran exclusivamente bajo su órbita.

En el caso de Olavarría, la falta de políticas públicas específicas ha derivado en el deterioro y la pérdida de los bienes patrimonializables, y en la consideración por parte de los habitantes de la ciudad del patrimonio como algo ajeno a su cotidianeidad. Por ejemplo, a pesar de las políticas culturales aplicadas en los períodos anteriores, se debe mencionar también que existe un significativo conjunto de bienes que se han perdido por inacción o incumplimiento de las normativas de protección local ${ }^{32}$. Como ya se ha destacado, las competencias de los municipios dependen del marco legal aplicable. En el caso de Olavarría, cabe preguntar si las gestiones municipales que adoptaron una actitud predominantemente pasiva y expectante no han faltado al deber de proteger el patrimonio cultural como un bien jurídico colectivo. Esto es así porque, en fecha posterior a la sanción de ordenanzas de protección patrimonial, se emitieron permisos de obra que regularizaron la alteración y la destrucción de obras patrimoniales.

Estas experiencias explican por qué algunos especialistas en patrimonio consultados sostienen que, para la política, el patrimonio es un tema lateral. En general "no se tiene ninguna conciencia ni importa nada, se va detrás del interés económico, al interés económico no le importa el patrimonio, al contrario, es una molestia" $y$, desde esta visión, ninguno de los gobiernos del período analizado se destacó por haber llevado adelante una política patrimonial que pusiera limitaciones a los intereses económicos privados (Oscar Luna ${ }^{33}$, entrevista, 20/02/2020).

Asimismo, se ha mencionado que no existen incentivos reales, ni económicos ni educacionales, para que la población cuide el patrimonio. En este sentido, los dirigentes políticos actúan "apagando incendios (...) a veces lo apagan bien, y a veces, llegan para las cenizas" (Mario Arabito, entrevista, 20/02/2020).

Las políticas culturales efectivamente llevadas a cabo en el partido siempre han sido las que surgieron a partir de la iniciativa personal del intendente de turno. Como ha señalado Juan Waldemar Wally, la gestión

32 Por mencionar sólo algunos ejemplos del período: el edificio de la ex Escuela Normal, demolida en 1994, fue vendida por el municipio a una empresa privada para la construcción de un supermercado en su lugar: o la vivienda conocida como Palacio de la Familia Domínguez, que fue prácticamente destruida en 2009 (se conserva sólo una porción de la vivienda original) para la construcción de un edificio en altura.

33 Arquitecto, especialista en el patrimonio arquitectónico del Partido de Olavarría. cultural "depende de los funcionarios de cultura, pero depende también del respaldo y del interés que tenga el intendente, si al intendente no le interesa..., el intendente tiene que tomar decisiones con recursos que siempre son escasos, nunca alcanza para todo" (entrevista, 18/02/2020). No obstante, como señala García Canclini (1987: 60) una buena política cultural

"no es la que asume en forma exclusiva la organización del desarrollo cultural en relación con las necesidades utilitarias de la mayoría -condición indispensable para que sea democrático-, sino que abarca también los movimientos de juego y experimentación, promueve las búsquedas conceptuales y creativas a través de las cuales cada sociedad se renueva".

Esto implica permitir y fomentar la participación de otros actores no involucrados en la gestión municipal o en las redes culturales institucionalizadas, tanto para la toma de decisiones como para el aporte de recursos humanos, materiales y simbólicos.

Como se ha mencionado al inicio de este artículo, la salvaguardia del patrimonio cultural al mediano y largo plazo está condicionada por el impacto y la continuidad de las políticas públicas. No obstante, se debe adicionar, que una gestión cultural local abordada desde la perspectiva de la sustentabilidad sociocultural implica también la incorporación de otras variables como la protección de la diversidad cultural, el apoyo a la producción de información sobre los distintos patrimonios y su difusión, y la promoción de la participación y apropiación comunitaria. Estas acciones deben ser llevadas adelante por los gobiernos de turno pero también exigidas y practicadas por la comunidad local.

Olavarría, 4 de Junio de 2021

\section{Agradecimientos}

En este trabajo se reproducen, parcialmente, resultados de la tesis doctoral de la autora, titulada "Sustentabilidad Sociocultural del Patrimonio urbano de la ciudad de Olavarría, Provincia de Buenos Aires, desde la década de 1980 hasta la actualidad". Asimismo, es parte de investigaciones desarrolladas en el marco de PATRIMONIA, Instituto INCUAPA (U.E. CONICET-UNICEN), con fondos del proyecto PICT 0551/16, dirigido por María Luz Endere y financiado por la ANPCyT.

\section{Bibliografía}

Arabito, M. (2009). 100 Obras del patrimonio arquitectónico olavarriense 1890-1970. Criterios para la elaboración de un inventario del patrimonio arquitectónico. En M. L. Endere y J.L. Prado (ed.), Patrimonio, Ciencia y Comunidad. Su abordaje en los 
Partidos de Azul, Tandil y Olavarría (pp. 67-73). Olavarría: UNICEN.

Arena, J., Cortés, J. y Valverde, A. (1967). Ensayo Histórico del Partido de Olavarría. Olavarría: Municipalidad de Olavarría.

Bolán, E. N. (2013). Las políticas culturales en América Latina en el contexto de la diversidad. En Hegemonía cultural y política de la diferencia (pp. 23-45). Buenos Aires: CLACSO.

Cantar, N. M. (2018). Entre lo normado y lo vivenciado. El caso del proceso de patrimonialización de la Escuela Normal "José Manuel Estrada" de Olavarría. Actas del Encuentro Internacional ciudades, território y patrimônio cultural, Mar del Plata, Facultad de Arquitectura, Urbanismo y Diseño, Universidad Nacional de Mar del Plata.

Cantar, N. M, Endere, M. L. y Zulaica, M. L. (2021). La "arqueología" de la sustentabilidad en la concepción del patrimonio cultural. Revista de Estudios Sociales, 75: 71-86.

Cardini, L. A. (2013). Políticas patrimoniales y patrimonio en la ciudad de Rosario, Argentina. Boletín de Antropología, 28 (46): 124-142.

Chaparro, M.G. (2017). Los avatares de una colección en ámbitos municipales: el Museo Etnográfico de Dámaso Arce (Olavarría, Argentina). Boletim do Museu Paraense Emilio Goeldi, Ciencias Humanas, 12 (2): 595-613.

Chaparro, M. G. y Curtoni, R. P. (2019). Arqueología y memoria en un ex Centro Clandestino de Detención y Tortura de Personas: Monte Pelloni, partido de Olavarría, Buenos Aires (Argentina). En Ataliva, V., Gerónimo, A. y Zurita, R. D. (eds), Arqueología Forense y Procesos de Memoria. Saberes y Reflexiones desde las prácticas (pp. 287-315). San Miguel de Tucumán: UNT.

Colombato, L. (2016). El derecho humano a los patrimonios culturales. Santa Rosa: Editorial de la Universidad Nacional de La Pampa.

Conforti, M. E., Mariano, M. y Endere, M. L. (2009). El cincelado del orfebre: patrimonio cultural inmaterial de Olavarría. El caso de la Escuela Municipal de Orfebrería y Artesanías Tradicionales. En M. L. Endere y J.L. Prado (ed.), Patrimonio, Ciencia y Comunidad. Su abordaje en los Partidos de Azul, Tandil y Olavarría (pp. 357-370). Olavarría: UNICEN.

Corbetta, P. (2007). Metodología y técnicas de investigación social. Madrid: McGraw-Hill/Interamericana de España.
Di Nucci, J. y Linares, S. (2016). Urbanización y red urbana argentina. Un análisis del período 1991-2010. Journal Ciencias Sociales, 4 (7): 4-17.

Duverger, M. (1981). Métodos de las Ciencias Sociales. Barcelona: Editorial Ariel.

Endere, M. L. (2000). Arqueología y Legislación en Argentina. Cómo proteger el patrimonio arqueológico. Serie Monográfica INCUAPA, 1. Tandil: UNICEN.

Endere, M. L. (2009). Algunas reflexiones acerca del Patrimonio. En M. L. Endere y J.L. Prado (ed.), Patrimonio, Ciencia y Comunidad. Su abordaje en los Partidos de Azul, Tandil y Olavarría (pp.19-48). Olavarría: UNICEN.

Endere, M. L., Chaparro, M. G. y Conforti, M. E., Prado, J., Pedrotta, V., Mariano, M. y Mariano, C. (2010). Olavarría antes de Olavarría. Una propuesta de difusión del patrimonio local en la provincia de Buenos Aires, Argentina. Actas del 1er Congreso Iberoamericano sobre Patrimonio Cultural: Experiencias metodológicas en el conocimiento del patrimonio.

Endere, M. L. y Colombato, L. C. (2017). The new unified Civil and Commercial Code and Cultural Heritage Protection in Argentina. International Journal of Cultural Property, 24: 79-99.

Endere, M. L. y Iturburu, M. (2010). La protección del patrimonio cultural en los municipios argentinos. Revista Jurídica, 5 (5):13-37.

Ferrer, E. y Pedrotta, V. (2006). Los corrales de piedra. Comercio y asentamientos aborígenes en las Sierras de Tandil, Azul y Olavarría. Tandil: Crecer Ediciones.

García Canclini, N. (1987). Políticas culturales y crisis de desarrollo: un balance latinoamericano. En García Canclini (ed.), Políticas culturales en América Latina (pp. 13-62). Ciudad de México: Editorial Grijalbo.

Guber, R. (2011). La etnografía. Método, campo y reflexividad. Buenos Aires: Siglo XXI.

Langiano, M., Merlo, J. y Pedrotta, V. (2009). El patrimonio arqueológico de la Antigua Frontera Sur: fuertes, fortines y tolderías. En M. L. Endere y J. L. Prado (ed.), Patrimonio, ciencia y comunidad. Su abordaje en los partidos de Azul, Olavarría y Tandil (pp. 235-258). Olavarría: INCUAPA, UNICEN.

Lanzelotti, S., Acuña Suarez, G., Arzani, H. (2016). El ordenamiento territorial y la gestión del Patrimonio Cultural del Partido de Mercedes, Buenos Aires, Argentina. REDSociales. Revista del Departamento de Ciencias Sociales, 3(1): 200-213. 
Levrand, N. (2009). Política Legislativa vs. Diversidad Cultural: El desafío de proteger nuestro Patrimonio Cultural. En G. Sozzo (comp.), La Protección de Patrimonio Cultural. Estudios socio jurídicos para su construcción (pp. 57-101). Santa Fe: Universidad Nacional del Litoral.

Levrand, N. E. y Endere, M. L. (2020) La incidencia del soft law en la reciente reforma a la ley de patrimonio histórico y artístico de Argentina. Revista Direito GV, 16 (2): 1-31.

Mandrini, R y Ortelli. S. (1992). Volver al país de los Araucanos. Buenos Aires: Sudamericana Joven Ensayo. Mariano, M. (2013). De representaciones, prácticas y fiestas bolivianas en las ciudades de Azul, Olavarría y Tandil, provincia de Buenos Aires: Un análisis desde la perspectiva del patrimonio cultural inmaterial. Tesis doctoral, UBA, Buenos Aires.

Martínez Nogueira R. (2010). La coherencia y la coordinación de las Políticas Públicas. Aspectos conceptuales y experiencias. En Proyecto de Modernización del Estado (ed.), Los Desafíos de la Coordinación y la integralidad de las políticas y gestión pública en América Latina (pp. 13-46). Buenos Aires: Jefatura de Gabinete de Ministerios. Presidencia de la Nación.

Marradi, A., Archenti, N. y Piovani, J. I. (2010). Metodología de las Ciencias Sociales. Buenos Aires: Cengage Learning Argentina.

Paz, C. (2009). El desarrollo de la minería en el partido de Olavarría. En M. L. Endere y J.L. Prado (ed.), Patrimonio, Ciencia y Comunidad. Su abordaje en los Partidos de Azul, Tandil y Olavarría (pp. 283-302). Olavarría: UNICEN.
Pedrotta, V. (2016). Recursos, Espacio y Territorio en las Sierras del Cayrú (Siglos XVI-XIX, Región Pampeana Argentina). En V. Pedrotta y S. Lanteri (dir.), La frontera sur de Buenos Aires en la larga duración (pp. 53-94). La Plata: Instituto Cultural de la Provincia de Buenos Aires Dirección Provincial de Patrimonio Cultural Archivo Histórico "Dr. Ricardo Levene".

Politis, G. (2012). Las poblaciones prehispánicas. En Otero, $\mathrm{H}$., Historia de la Provincia de Buenos Aires. Población, Ambiente y Territorio (pp. 211-247). La Plata: UNIPE, Editorial Universitario y Edhasa.

Politis G.G., Gutiérrez M.A., Rafuse D.J. y Blasi A. (2016). The Arrival of Homo sapiens into the Southern Cone at 14,000 Years Ago. PLOS ONE, 11(9): e0162870.

Rodríguez, L.G. (2015). Cultura y dictadura en Argentina (1976-1983): estado, funcionarios y políticas. Anuario Colombiano de Historia Social y de la Cultura, 42 (2): 299-325.

Sassone, S. (1981). Azul, Olavarría, Tandil: un sistema urbano. Buenos Aires, Argentina. Buenos Aires: OIKOS Asociación para la Promoción de los Estudios Territoriales y Ambientales.

Scribano, A. O. (2008). El proceso de investigación social cualitativo. Buenos Aires: Prometeo Libros.

Shore, C. (2010). La antropología y el estudio de la política pública: reflexiones sobre la "formulación" de las políticas. Antípoda. Revista de Antropología y Arqueología, 10: 21-49. 